\title{
Clinical trial design for endovascular ischemic stroke intervention
}

Osama O. Zaidat, MD, MS

David S. Liebeskind, MD

Randall C. Edgell, MD

Catherine $\mathrm{M}$.

Amlie-Lefond, MD

Junaid S. Kalia, MD

Andrei V. Alexandrov,

MD

Correspondence \& reprint requests to Dr. Zaidat: szaidat@mcw.edu

\section{ABSTRACT}

Background: Randomized, double-blinded, placebo-controlled trials have significant impact on clinical practice. The ultimate goal of a clinical trial of therapy for acute ischemic stroke (AIS) is to compare 2 interventions. Challenges may include interventional therapy standardization, enrollment rate, patient selection, biases, data and safety monitoring, reporting, and financial and logistical support.

Method: Selected randomized and single-arm prospective AIS trial designs. Clinical trial elements and their challenges are reviewed. Innovative designs and proposed recommendations to overcome some of the specific challenges and limitations are discussed.

Results: AIS therapy trials have specific challenges related to ethical issues, enrollment rate, outcome measures, limited time to treatment, efficacy, safety, and limited or variable operator experience with complex technology in a delicate end organ. Proposed suggestions for improving trial design include the following: incorporation of a lead-in phase; careful patient and outcome measure selection; historical, concurrent, or hybrid controls; open data access; and a Bayesian approach. An open data paradigm may facilitate creation of computerized prediction models for future trials (minimizing cost by decreasing sample size or providing futility analyses and directing resources to other trials). Collaborative, consortium, and network infrastructures may allow more effective and efficient study completion. Self-learning, self-correcting trials with intrinsic flexibility to adapt may help future clinical trial design in AIS.

Conclusion: The randomized clinical trial design in AIS endovascular therapy is challenging. Lead-in phases, careful patient selection, use of innovative outcome measures, control groups, and newer clinical trial design may enhance conduct of future trials, their validity, and their results. Neurology ${ }^{\circledR} 2012 ; 79$ (Suppl 1):S221-S233

\section{GLOSSARY}

AIS = acute ischemic stroke; BI = Barthel Index; CER = comparative effectiveness research; $\mathbf{C R F}=$ case report form; $\mathbf{E T}=$ endovascular therapy; FDA = US Food and Drug Administration; IC = informed consent; IMS = Interventional Management of Stroke; IRB = institutional review board; $\mathbf{m R S}=$ modified Rankin Scale score; NIHSS = NIH Stroke Scale; RCT = randomized controlled trial; $\mathbf{T I C I}=$ thrombolysis in cerebral ischemia; $\mathbf{T I M I}=$ thrombolysis in myocardial ischemia; $\mathbf{t P A}=$ tissue plasminogen activator.

Clinical trial use in medicine dates back to 1931, when the effect of sanocrysin in pulmonary tuberculosis was studied, with allocation determined by the flip of a coin. ${ }^{1}$ Clinical trials now have dedicated specialists in all aspects of trial design.

The effect of clinical trials on clinical practice has been shown previously. In ischemic stroke secondary prevention, publication of the results of the Warfarin Aspirin Symptomatic Intracranial Disease (WASID) Trial (comparing aspirin to warfarin for intracranial stenosis, and showing high recurrent stroke with the use of aspirin or warfarin) was followed by publication of a registry for use of a new intracranial stent, leading to a significant increase (by 763\%) in the frequency of intracranial stenting. ${ }^{2-4}$ This may show the reverse impact on the use of intracranial stenting in treating intracranial stenosis, following the more recent publication of a prospective randomized, controlled clinical trial comparing intracranial stent to optimal medical

From the Departments of Neurology (O.O.Z., C.M.A.L.), Neurosurgery (O.O.Z.), and Radiology (O.O.Z.), Medical College of Wisconsin and Froedtert Hospital, Milwaukee; Department of Neurology (D.S.L.), UCLA, Los Angeles, CA; Department of Neurology (J.S.K.), St. Louis University, St. Louis, MO; and Department of Neurology (A.V.A.), University of Alabama Hospital, Birmingham.

Go to Neurology.org for full disclosures. Disclosures deemed relevant by the authors, if any, are provided at the end of this article. 
therapy in $\geq 70 \%$ of symptomatic stenosis cases, with superiority of medical therapy. ${ }^{5}$ The International Subarachnoid Hemorrhage Trial (ISAT) results, which showed superiority of endovascular transarterial coil embolization over surgical clipping in ruptured cerebral aneurysms, has changed the way we treat aneurysm nowadays. ${ }^{6}$ The number of aneurysms treated with coiling has increased by $315 \%$ between 2001 and $2008 .^{7}$

In the past half century, the number of controlled clinical studies has increased as it became the preferred method for establishing clinical evidence. From 1995 to 1999 there were 178 controlled trials of therapy for acute ischemic stroke (AIS). ${ }^{8}$ The trend in AIS trials has been toward an increase in sample size and a decrease in time window. ${ }^{9}$ Despite improvements, AIS trials lag behind other specialties such as oncology in the level of design sophistication to overcome persistent limitations. ${ }^{10}$ Moreover, differences exist between drugs and devices in terms of regulation and approval by regulatory agencies. ${ }^{11}$ Drugs typically enter the market after a randomized controlled trial (RCT) shows safety and clinical efficacy. An RCT of endovascular AIS therapy is challenging to conduct; only one phase III AIS endovascular clinical trial (Prolyse in Acute Cerebral Thromboembolism [PROACT] $\mathrm{II}^{12}$ ) has been completed. Interventional Management of Stroke III (IMS III) ${ }^{13}$ is a phase III trial comparing an interventional approach to standard of care (IV recombinant tissue plasminogen activator) that was halted recently and will be published in the near future. Designing AIS endovascular interventional clinical trials is a daunting task, facing several challenges such as the best design, sample size, rate of recruitment, choice of outcome measure, evolving iterative device technology, informed consent, procedure standardization, and other logistic issues. ${ }^{14}$ For additional references, we refer interested readers to Stroke Therapy Academic Industry Roundtable (STAIR) statements and the Clinical Trials in Neurology textbook. ${ }^{15-22}$

ETHICAL CONSIDERATIONS Some of the ethical issues that may be encountered are the presence or lack of equipoise, ${ }^{23}$ the randomization process, the cost of care within the trial, and informed consent.

As experience with endovascular therapy (ET) improves, efficacy becomes supported by anecdotal evidence that, by some investigators, precludes enrollment. The fact that there is no firm evidence to support which patients may or may not benefit from ET provides equipoise to legitimately conduct an RCT. These issues may be addressed by including newer devices and scientifically convincing interested parties of the presence of equipoise.

Moreover, the randomization process may be implemented to allow more patients to be randomized to intervention. This would be by using different rates of randomization, imaging-based randomization, concurrent controls, and historical controls (see the following sections).

Informed consent. Detailed discussion of the informed consent (IC) in AIS trials is beyond the scope of this review. The sophistication of the ET, standard of care, and variability of the natural history of untreated patients are all elements that make the process of emergency IC complex. ${ }^{24,25}$ Considering emergency waiver of consent in some cases (such as basilar artery thrombosis and coma) but not in all cases would require public discussion for allowing community, next of kin, or legal representative consent; in other, milder stroke cases, direct IC can be obtained. ${ }^{24,25}$ Telestroke may also allow consenting patients' families remotely and enrollment of drip-andship patients.

Ethics committee and institutional review board. The federal government is evaluating the current rules for conducting research in human subjects, which may help to improve institutional review board (IRB) process in general and streamline AIS trial research without undue bureaucracy. ${ }^{26}$ The US Department of Health and Human Services is considering modification of IC - to be easier to understand, to provide uniform data protection, and to avoid duplicate paperwork-as well as electronic case report forms (CRFs), a more systematic approach to collecting adverse event data, to match the review requirements with the risk posed and enable multicenter trials to be supervised by a single IRB. ${ }^{26}$

\section{CLINICAL TRIAL DESIGN CONSIDERATIONS} The clinical trial definition of statistical power and classification of various phases is summarized in table 1 , with a typical timetable of a medical device study summarized in the figure. ${ }^{27}$ Introduction of medical devices to the market may start with preclinical animal, angiographic, clinical, and histologic studies, sample size calculation, and then establishment of the trial protocol, CRF design, budget, clinical trial 
Table 1 Statistical power and typical phases of clinical trials

\begin{tabular}{|c|c|}
\hline & Comment \\
\hline \multirow{6}{*}{$\begin{array}{l}\text { Statistical power: the probability of a statistical } \\
\text { test to detect a significant difference between } \\
2 \text { treatment arms where a true one exists at a } \\
\text { given significance level and sample size }\end{array}$} & Factors affecting the power: \\
\hline & - Sample size \\
\hline & - Choice of significance level \\
\hline & - Choice of study endpoint \\
\hline & - Endpoint cutoff level/dichotomization choice \\
\hline & $\begin{array}{l}\text { - Treatment effect }(\delta) \text {, absolute risk reduction: } 5 \%, 10 \%, 15 \% \text { ? } \\
\text { (Overestimating the } \delta \text { reduces the sample size at the expense of not } \\
\text { finding true subtle effect of the therapy) }\end{array}$ \\
\hline \multirow[t]{4}{*}{ Phase I: 20-50 } & - Exploratory phase \\
\hline & - Toxicity, tolerance, and dosing \\
\hline & $\begin{array}{l}\text { - Dose escalation experiments to identify a safe dose (maximally } \\
\text { tolerated doses) }\end{array}$ \\
\hline & - Can be used for sample size calculation \\
\hline \multirow[t]{3}{*}{ Phase II: $50-150$} & - Explanatory phase \\
\hline & - Efficacy and safety exploration \\
\hline & - Assessment of response rates for sample size calculation \\
\hline \multirow[t]{3}{*}{ Phase IIB: $1,000-3,000$} & $\begin{array}{l}\text { - 5-year study prior to incorporating device in randomized, controlled Phase } \\
\text { III trial }\end{array}$ \\
\hline & - Can be nested in Phase III trial \\
\hline & $\begin{array}{l}\text { - For devices that have not been compared to standard of care but obtained } \\
510(k) \text { FDA approval }\end{array}$ \\
\hline \multirow[t]{3}{*}{ Phase III: $250-4,000$} & - Pragmatic phase \\
\hline & - Comparison with standard of care \\
\hline & - Randomized with 2 or more arms \\
\hline Phase IV: in thousands & - Observational phase \\
\hline \multirow[t]{4}{*}{ Postmarketing } & - Postmarketing prospective surveillance \\
\hline & - Reliable replication in real world \\
\hline & - Self-reported data \\
\hline & - Design, oversight, and control of data may vary \\
\hline
\end{tabular}

Abbreviation: FDA = Food and Drug Administration.

agreement, site selection, investigators' meeting, IRB approval, site initiation visit, audit, midterm analysis, study completion, queries and data cleaning, and study closure.

Classic trial design phases are as follows:

Preclinical—animal safety/feasibility study: devices are tested for trackability, deliverability, and performance of the intended use, with histopathologic confirmation of safety and clot removal.

Phase I- human safety/feasibility and efficacy exploratory device trial: a classic device study is within 8-hour time/imaging/combined windows of AIS patients with NIH Stroke Scale (NIHSS) score $\geq 8$. Proposed number of patients to be enrolled is 40 to 50 .

Phase IIA— human safety, feasibility, and efficacy exploratory device trial: a study within 8-hour time/ imaging/combined windows of AIS patients with NIHSS score $\geq 8$, with noninferiority/equivalency comparison to an existing device approved by the US
Food and Drug Administration (FDA). Proposed number of patients to be enrolled is 75 to 125 per arm (total of 150-250).

Phase IIB - device use and application study for 3 to 5 years following FDA approval, to test real-life safety and feasibility, to allow introduction of new design iterations, and to enhance clinical application before planning the RCT. Proposed number is 1,000 to 3,000 .

Phase III-RCT efficacy trial with lead-in phase of AIS ET vs the best clinical care.

Phase IV-postmarketing study to allow monitoring of the device in real-world practice. Table 2 shows select AIS trials and their designs.

Comparative vs single-arm studies. Prospective singlearm studies. The FDA pathway to approval of such devices has been via the $510(\mathrm{k})$ process, based on safety and angiographic revascularization endpoints. The evidence provided by single-arm prospective AIS 


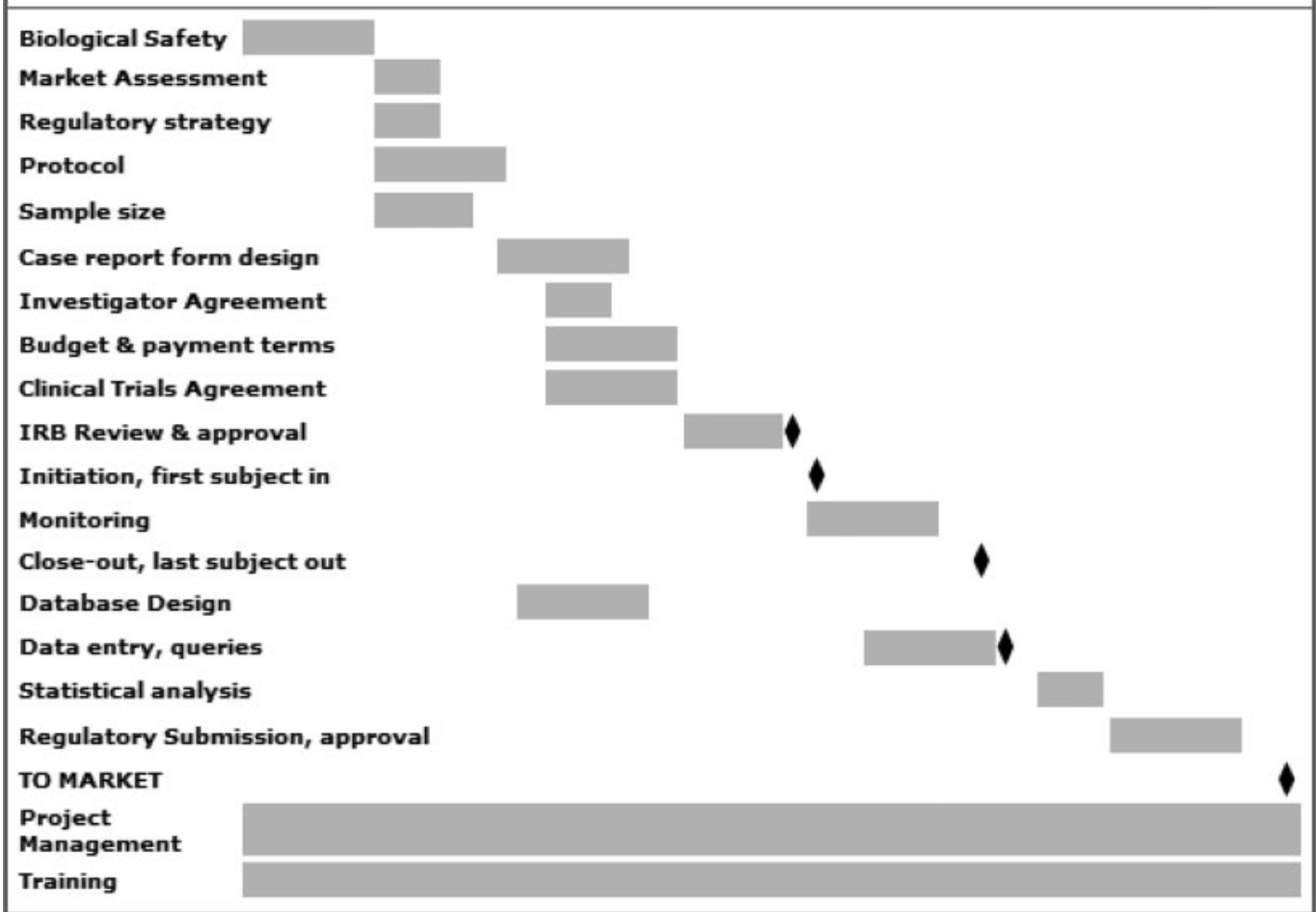

Reprinted with permission from www.clinicaldevice.com/indexOLD.html.

device trials and FDA clearance $(510(\mathrm{k}))$ has permitted incorporation of ET in routine AIS treatment. Anecdotal evidence thus became convention. However, increasing demand from the stroke neurology community for a higher level of scientific evidence resurrected interest in $\mathrm{RCTs}{ }^{28}$ Challenges to stroke device RCT design need to be considered, given the complexity of ET (variability and lack of standardization) vs medical care (simple and standardized). An additional consideration is to conduct a large postmarketing study following the phase II $(510(\mathrm{k})$ approval) trial, allowing time to standardize application of the new device and its design reiteration prior to RCT with an embedded lead-in phase.

Comparative effectiveness research. According to the Institute of Medicine, comparative effectiveness research (CER) is defined as "the generation and synthesis of evidence that compares the benefits and harms of alternative methods to prevent, diagnose, treat, and monitor a clinical condition or to improve the delivery of care. The purpose of CER is to assist consumers, clinicians, purchasers, and policy makers to make informed decisions that will improve health care at both the individual and population levels." ${ }^{29}$ More recently, the US Congress has taken CER seriously and boosted its funding. ${ }^{30}$ However, CER is not easily applied to complex ET, and RCT design needs to be addressed as a prerequisite.

ENDOVASCULAR AIS THERAPY TRIAL CHALLENGES AND CONSIDERATIONS Sample size. Estimation of sample size based on statistical power (table 1) is a key to finding treatment effect. The sample size estimation requires 4 elements: interventional therapy presumed effect; standard of care event rate; power needed $(0.7,0.8,0.9)$; and significance level $(\alpha: 0.05,0.10)$. Small sample size may partly explain failure in many stroke trials. ${ }^{31}$ One report showed that $72 \%$ of AIS phase III trials were underpowered to $<0.90$ level and overestimated their intervention effect or underestimated the control arm event rate. ${ }^{31}$ The possibility of not finding a treatment effect based on an optimistic assumption should be weighed against the future ramifications of a negative trial.

Enrollment challenges. Investigators often use the "1 patient per month per center" enrollment rate rule. One other assumption is the rule of thirds: centers will enroll approximately $1 / 3$ of the number of patients predicted; $1 / 3$ of the centers will enroll their target numbers; and $1 / 3$ will perform far below expectations. ${ }^{32}$ Some of the proposed solutions are summarized in table 3 . These include increasing the proportion of patients randomized to ET; perform- 
Table 2 Selected endovascular acute ischemic stroke clinical trials and their design

\begin{tabular}{|c|c|c|}
\hline Trial & $\begin{array}{l}\text { Sample size/ } \\
\text { no. of centers }\end{array}$ & Design \\
\hline \multirow{5}{*}{$\begin{array}{l}\text { Mechanical Embolus Removal in Cerebral } \\
\text { Ischemia (MERCI) trial }{ }^{47}\end{array}$} & $141 / 25$ & Phase II \\
\hline & & Single arm \\
\hline & & Multicenter \\
\hline & & Noncontrolled, nonrandomized \\
\hline & & Open label \\
\hline \multirow{4}{*}{$\begin{array}{l}\text { SOLITAIRE FR With the Intention For } \\
\text { Thrombectomy (SWIFT) Study }\end{array}$} & Planned 250 & Phase II \\
\hline & & Multicenter \\
\hline & & $\begin{array}{l}\text { Randomized (parallel assignment, 1:1, Merci device } \\
\text { vs Solitaire device) }\end{array}$ \\
\hline & & Open label \\
\hline \multirow{2}{*}{$\begin{array}{l}\text { Thrombectomy REvascularization of Large Vessel } \\
\text { Occlusions in Acute Ischemic Stroke (TREVO) }{ }^{61}\end{array}$} & 60 & Phase I pilot \\
\hline & & Single-arm, prospective \\
\hline \multirow{6}{*}{$\begin{array}{l}\text { Randomized Trial Evaluating Performance of the } \\
\text { Trevo Retriever Versus the Merci Retriever in } \\
\text { Acute Ischemic Stroke (TREVO2)62 }\end{array}$} & 178 & Phase II \\
\hline & & $\begin{array}{l}\text { Randomized Trevo device with Merci; ongoing } \\
\text { prospective study }\end{array}$ \\
\hline & & Endpoint classification: safety/efficacy study \\
\hline & & Intervention model: parallel assignment \\
\hline & & Masking: open label \\
\hline & & Primary purpose: treatment \\
\hline \multirow{5}{*}{$\begin{array}{l}\text { Prolyse in Acute Cerebral Thromboembolism } \\
\text { (PROACT) II Trial } 12\end{array}$} & $180 / 54$ & Phase III \\
\hline & & Multicenter \\
\hline & & Controlled, randomized (2:1 placebo) \\
\hline & & Open-label \\
\hline & & Blinded follow-up \\
\hline \multirow[t]{4}{*}{ Interventional Management of Stroke (IMS) III ${ }^{13}$} & $900 / 60$ & Phase III \\
\hline & & Multicenter \\
\hline & & Controlled, randomized (2:1 placebo) \\
\hline & & Open-label \\
\hline \multirow{4}{*}{$\begin{array}{l}\text { Mechanical Retrieval and Recanalization of } \\
\text { Stroke Clots Using Embolectomy (MR RESCUE) }{ }^{35}\end{array}$} & $120 / 30$ & Phase II \\
\hline & & Multicenter \\
\hline & & Controlled, randomized (1:1) \\
\hline & & $\begin{array}{l}\text { To identify, on basis of MR RESCUE protocol, } \\
\text { patients that would benefit the most }\end{array}$ \\
\hline \multirow[t]{5}{*}{ Penumbra Pivotal Stroke Trial ${ }^{46}$} & $125 / 24$ & Phase II \\
\hline & & Single arm (MERCI Trial as historical control) \\
\hline & & Multicenter \\
\hline & & Nonrandomized \\
\hline & & Open-label \\
\hline \multirow{4}{*}{$\begin{array}{l}\text { Assess the Penumbra System in the Treatment of } \\
\text { Acute Stroke (THERAPY) trial }{ }^{37}\end{array}$} & 692 & Phase III \\
\hline & & Multicenter \\
\hline & & Controlled \\
\hline & & Randomized (Penumbra vs standard of care, $1: 1$ ) \\
\hline
\end{tabular}

Randomized (Penumbra vs standard of care, 1:1) 
Table 3 Challenges for planning interventional management of acute ischemic stroke trials

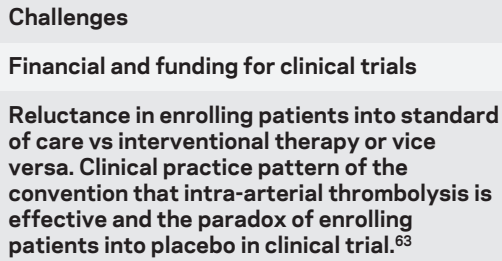

Informed consent

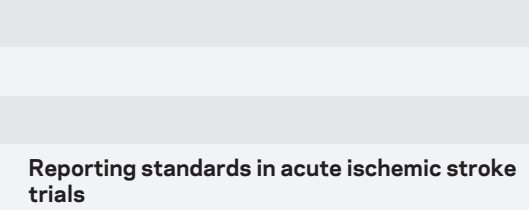

Access to the data

\section{Suggestions to overcome the challenges}

Joint sponsorship between government and industry

1. Different rate of randomization to endovascular vs medical therapy, similar to PROACT and IMS, 2:1. The new concept of randomization between existing approved devices vs newer device is an improvement over the single-arm studies but would not compare the endovascular therapy to standard of care

2. Selection of sites that favor endovascular therapy vs sites that favor standard medical therapy (needs statistical adjustment)

3. Selecting and identifying the subgroup that would benefit the most from endovascular therapy to reduce the sample size by having the largest potential difference in outcome: e.g., 0-4.5 h IV patients with NIHSS $\geq 8$ with large penumbra or large-vessel occlusion on CTA or clot length on ultrathin plain CT scan to randomize to IV vs IV and IA (THERAPY Trial NCT01429350)

4. Use of historical control from other studies, e.g., PROACT study matched group from IV and placebo cohorts of NINDS and ECASS rtPA IV trials

5. Independent group of clinical trialists to be involved with industrysponsored trials to adhere to the same standard of reporting

6. Independent postmarketing clinical registries; industry-, FDA-, or CMSsponsored or cosponsored with an independent investigator

7. Lead-in/roll-in phase as standard part of the RCT

1. Increase the number of participating sites (without compromise in quality)

2. Stroke Interventional Trials Consortium

3. Drip-and-ship enrollment with telestroke

4. Innovative statistical method that can lower sample size without compromise in quality; use of different types of control, choice of outcome measure, Bayesian method

1. Community consent

2. Next of kin consent

3. Verbal (over the phone) consent, given the timely need to intervene

4. Telestroke consent

Adhere to standards in reporting acute ischemic trials and maintain consistency in inclusion criteria and clinical and angiographic outcomes

Allow high-enrolling sites with the lowest deviation to be on the publication committee

Controlled access to the data of multiple trials from multiple manufacturer and sponsors to reliable research groups

Abbreviations: CMS = Centers for Medicare \& Medicaid; CTA = CT angiography; ECASS = European Cooperative Acute Stroke Study; FDA = US Food and Drug Administration; IMS = Interventional Management of Stroke; NIHSS = NIH Stroke Scale; NINDS = National Institute of Neurological Disorders and Stroke; PROACT = Prolyse in Acute Cerebral Thromboembolism; RCT = randomized controlled trial; rtPA = recombinant tissue plasminogen activator.

ing an unbiased trial; emphasizing the presence of equipoise; having a flexible protocol in terms of inclusion criteria and ability to include device iterations; replacing low-enrolling sites; and allowing for high-enrolling sites with low protocol deviations to be part of the publication committee. Telestroke has the potential for allowing drip-and-ship patient enrollment.

Time vs imaging-based enrollment (responders vs nonresponders paradigm). There is a controversy about using time from symptom onset vs multimodal imaging vs using both as the main inclusion criteria for endovascular AIS trials. ${ }^{33} \mathrm{MRI}$ diffusion and perfusion sequences are used in triaging patients with AIS for ET. ${ }^{33}$ The imaging criteria of interest to use for randomization (the amount of mismatch) is highly dependent on technical and software factors. Moreover, in the bridging IMS trial, outcome has been found to be time-dependent. ${ }^{34}$ However, the Mechanical Retrieval and Recanalization of Stroke Clots Using Embolectomy (MR RESCUE) study, testing whether MRI selection of patients for AIS interventional therapy (using the Merci or Penumbra device), is near completion and will help to clarify the imaging role in future trial design. ${ }^{35}$

More recently, the clot length as measured on an ultrathin head CT scan has been correlated with lack of response to systemic IV recombinant tissue plas- 
minogen activator therapy when the clot length exceeded $8 \mathrm{~mm} .{ }^{36}$ Using clot length as the main inclusion criterion, a randomized clinical trial (the THERAPY Trial) has been launched. ${ }^{37}$ Theoretically, responder-based selection may reduce the sample size, increase power, and more likely find a treatment effect. Disadvantages may include slow enrollment, limited generalizability, and prolonged duration.

Selection bias. Strict selection criteria would limit the generalization of the trial results, and liberal selection criteria may dilute the effect of the intervention of interest. Trials with unclear subject allocation blinding and randomization method showed larger estimates of effect when compared with concealment trials. ${ }^{38}$ Investigator meetings may play a pivotal role in ensuring minimal selection bias to improve results credibility.

Choice of study endpoint: angiographic and clinical outcomes. Angiographic revascularization. The most commonly used successful revascularization endpoints are the Thrombolysis in Myocardial Ischemia (TIMI) and Thrombolysis in Cerebral Ischemia (TICI) grading scales. Scale outcomes of TIMI 2, TICI 2, TICI 2b, or higher have all been considered successes. More recently, in the SWIFT trial (Solitaire FR With Intention for Thrombectomy, a trial comparing the efficacy and safety of the Solitaire Stent Retriever with the Merci device), the design was based on recanalization success. This was defined as successful recanalization of TIMI 2 or higher without symptomatic intracranial hemorrhage. ${ }^{39,40}$ Adhering to a well-defined angiographic grading scale is important to enable comparison of trials.

Clinical outcome measure. Modified Rankin Scale (mRS; a 7-point scale) score at day 90 has been commonly used for the primary clinical endpoint in AIS trials (table 4). Other endpoints used in stroke trials are Barthel Index (BI), NIHSS, and global scale (combining more than 1 scale) (table 5). ${ }^{41,42}$ One study that compared the statistical power for a range of $\mathrm{mRS}, \mathrm{BI}$, and global scale on the basis of data from the Glycine Antagonist in Neuroprotection International Trial on detecting a treatment difference found that the mRS is the most powerful scale. ${ }^{41} \mathrm{On}$ the basis of the authors' analysis, the statistical power improved by using $\mathrm{mRS}$ vs $\mathrm{BI} \geq 60$ and reducing sample size by $84 \%$ (73\% for patient-specific BI and $81 \%$ for global score). A similar finding was established by National Institute of Neurological Disorders and Stroke investigators, as the mRS dichotomized at $\leq 1$ was found to be the most effective measure in identifying effectiveness of IV tissue plasminogen activator (tPA). ${ }^{43}$ Another choice is endpoint trichotomization

\begin{tabular}{|ll|}
\hline Table 4 & \multicolumn{1}{c|}{ The modified Rankin Scale } \\
Scale & Clinical description \\
\hline 0 & No symptoms at all and no disability \\
1 & $\begin{array}{l}\text { No significant disability despite some symptoms; } \\
\text { able to carry out all usual daily duties and activities }\end{array}$ \\
2 & $\begin{array}{l}\text { Slight disability; unable to carry out all previous } \\
\text { activities, but able to look after own affairs } \\
\text { without assistance }\end{array}$ \\
3 & $\begin{array}{l}\text { Moderate disability; requiring some help, but able } \\
\text { to walk without assistance }\end{array}$ \\
4 & $\begin{array}{l}\text { Moderately severe disability; unable to walk } \\
\text { without assistance and unable to attend to own } \\
\text { bodily needs without assistance }\end{array}$ \\
5 & $\begin{array}{l}\text { Severe disability; bedridden, incontinent, and } \\
\text { requiring constant nursing care and attention }\end{array}$ \\
6 & Dead
\end{tabular}

(for example, $m R S \leq 1, \leq 2$, and more than 2 , or $\mathrm{BI}$ $\geq 60$, $\geq 95$, and less than 60 ), shift analysis of mRS shows how many people improve to a better scale, or patient-specific based on initial stroke severity may be more sensitive given the significant heterogeneity of the AIS population. ${ }^{44}$ An example of the importance of the choice of primary clinical outcome endpoint is evident in the European Cooperative Acute Stroke Study II trial..$^{45}$ If the primary endpoint selected for the trial was $\mathrm{mRS}$ shift analysis or dichotomized at $\leq 2$, then the trial would have been positive in favor of IV-tPA. ${ }^{45}$

Novel clinical trial designs. Choices of control group. The gold standard is the contemporary randomized control, where participants are allocated randomly to treatment or control groups across all participating sites at all time points.

The use of this gold standard control type may lead to selection bias or low enrollment based on investigator belief; hence, concurrent control may be considered. The concurrent control arm would be from participants enrolled approximately at the same time from centers that do not adopt ET in their pathway and protocol or at which it is not feasible to send patients to ET because of time constraints. The concurrent control has the potential advantages of higher enrollment rate, shorter trial period, and method of allocation based on physician-/centerspecific conventions. However, it is associated with an inherent selection bias.

Another type of control is historical control. Historical controls are comparable subjects from a previous study with similar inclusion and exclusion criteria that did not include the interventional therapy of interest, compared with a new intervention used in a single-arm prospective trial. An example of historical control is when the Penumbra Pivotal Trial enrolled a similar number of patients and used inclusion/exclusion criteria similar to those in the MERCI 
Table 5 Clinical and angiographic outcome choices in selected acute ischemic stroke clinical trials

Scale
Modified Rankin Scale (mRS) at 90 days \pm 30
days (the most commonly used primary
endpoint functional disability measure)

NIHSS at 1 day, 7 days, 30 days, 90 days \pm 30 days (majority of the trials used NIHSS as a secondary endpoint)

Global test at 30 and 90 days (both primary
and secondary endpoints)

Angiographic recanalization; used as primary endpoint in single-arm device studies at 90 days \pm 30 days

Trial

ECASS III, 64 NINDS65

PROACT II, 12 IMS III,

$\mathrm{MERCl},{ }^{47}$

Penumbra, ${ }^{46} \mathrm{MR}$

RESCUE ${ }^{35}$

SAINT66

PROACT II, ${ }^{12}$ GAIN ${ }^{41}$

PROACT II12

MELT 67

ECASS III, ${ }^{64}$ NINDS ${ }^{65}$

PROACT $\|^{12}$

ECASS III ${ }^{64}$
NINDS, $^{65}$ MELT $^{67}$
MERCI $^{47}$

Penumbra Pivotal ${ }^{46}$

IMS IIII3

ECASS $111,{ }^{64}$ NINDS $^{65}$

Penumbra Pivotal ${ }^{46}$
MRRESCUE, ${ }^{35}$
NINDS, ${ }^{65}$
NINDS $^{65}$

PROACT $\|^{12}$

MELT67

MERCI ${ }^{47}$

IMS IIII3

Penumbra ${ }^{46}$

SWIFT 39

PROACT $\|^{12}$

PROACT II12

The most commonly used definition is declin in NIHSS by 4 points, linked to new cranial hemorrhage on follow-up CT scan within 18-

$36 \mathrm{~h}$ from randomization or any new

deterioration following randomization related

to new hemorrhage

\section{Endpoint choice}

Binary dichotomization $\leq 1$

Binary dichotomization $\leq 2$

mRS shift analysis

Trichotomization ( $\geq 60,<60, \geq 95$ )

Patient-specific

$\geq 60$ and $\geq 95$

$\geq 95$

$\geq 95$

NIHSS $\leq 1$, or $\geq 50 \%$ improvement from baseline at 90 days

NIHSS $\leq 1$ or improved by $\geq 8$ points

NIHSS $\leq 1$

NIHSS improved by $\geq 10$ points at 30 and 90 days

NIHSS $\leq 1$ or improved by $\geq 10$ points at discharge and 30 days

NIHSS $0-2$ at $24 \mathrm{~h}$

Inclusion of multiple scales: mRS, BI, NIHSS: NINDS: $(B I \geq 95, R S \leq 1, N I H S S \leq 1$, and Glasgow Outcome Scale = 1)

Composite endpoint of NIHSS $\leq 1$ or improved by $\geq 10$ points or $m R S \leq 2$ at 30 days

Global test, secondary endpoint at 90 days

Global test, primary endpoint at 90 days

TIMI 2 or more; TIMI 2 when flow re-established to both $\mathrm{M} 1$ and $\mathrm{M} 2$ or partial TIMI 2 when flow present to either segment

Close to $\mathrm{TICl}$ : no recanalization; partial recanalization $<50 \%$ in the affected territory; partial recanalization $50 \%$ and over in the affected territory; and complete recanalization

TIMI 2 or more, different operating definition

TIMI, AOL, and TICI

TIMI 2 or higher, different operating definition

SRNH: successful, greater than TIMI 2 recanalization without symptomatic hemorrhage

Hemorrhagic infarction: any petechial or smal confluent hemorrhages within larger region of hypodense ischemia

Parenchymatous hematoma: homogeneous areas of hemorrhage, with or without mass effect or intraventricular extension

sICH: hemorrhagic transformation causing neurologic worsening of $\geq 4$ points in the NIHSS or a 1-point deterioration in level of consciousness within $24 \mathrm{~h}$ of treatment

MELT ${ }^{67}$
sICH: any new ICH within $24 \mathrm{~h}$, with neurologic decline evidenced by objective signs or an increase of $\geq 4$ points in NIHSS score 


\begin{tabular}{|c|c|c|c|}
\hline Table 5 & Continued & & \\
\hline \multirow[t]{11}{*}{ Scale } & & Trial & Endpoint choice \\
\hline & & NINDS65 & $\begin{array}{l}\text { sICH: any new ICH within } 36 \mathrm{~h} \text {, with any neurologic } \\
\text { decline }\end{array}$ \\
\hline & & ECASS III64 & Radiologic CT of head definitions: \\
\hline & & & $\begin{array}{l}\text { I. Hemorrhagic infarction-l: small petechiae along } \\
\text { the margins of the infarct }\end{array}$ \\
\hline & & & $\begin{array}{l}\text { II. Hemorrhagic infarction-II: more confluent } \\
\text { petechiae within the infarcted area, but without } \\
\text { space-occupying effect }\end{array}$ \\
\hline & & & $\begin{array}{l}\text { III. Parenchymal hematoma-I: a hematoma in } \leq 30 \% \text { of } \\
\text { infarcted area with slight space-occupying effect }\end{array}$ \\
\hline & & & $\begin{array}{l}\text { IV. Parenchymal hematoma-II: a dense hematoma } \\
>30 \% \text { of the infarcted area with significant } \\
\text { space-occupying effect, or any hemorrhage } \\
\text { outside the infarcted area }\end{array}$ \\
\hline & & & $\begin{array}{l}\text { sICH (ECASS III): any extravascular blood within the } \\
\text { brain/cranium that was associated with a decline of } \\
\geq 4 \text { points in NIHSS or that led to death and was } \\
\text { identified as the predominant cause of the neurologic } \\
\text { deterioration }\end{array}$ \\
\hline & & MERCI trial 47 & $\begin{array}{l}\text { sICH: A decline of } \geq 4 \text { points in the NIHSS within } 24 \mathrm{~h} \\
\text { with any hemorrhage identified on CT head: petechial } \\
\text { bleeding, hematoma, or subarachnoid hemorrhage } \\
\text { (SAH) and any ICH/SAH in which NIHSS scores were } \\
\text { not available or mortality occurred }\end{array}$ \\
\hline & & Penumbra Pivotal ${ }^{46}$ & $\begin{array}{l}\text { sICH: CT evidence of a bleed with a 4-point } \\
\text { deterioration in the NIHSS score within } 24 \mathrm{~h} \text { of the } \\
\text { procedure }\end{array}$ \\
\hline & & IMS $\|^{113}$ & $\begin{array}{l}\text { sICH: Any ICH within } 24 \text { h of randomization with } \geq 4 \text { - } \\
\text { point decline in NIHSS }\end{array}$ \\
\hline
\end{tabular}

Abbreviations: $\mathrm{AOL}=$ arterial occlusive lesion; $\mathrm{BI}=$ Barthel Index; ECASS = European Cooperative Acute Stroke Study; GAIN = Glycine Antagonist in Neuroprotection; ICH = intracranial hemorrhage; IMS = Interventional Management of Stroke; MELT = Middle Cerebral Artery Embolism Local Fibrinolytic Intervention Trial; MERCI = Mechanical Embolus Removal in Cerebral Ischemia; MR RESCUE = Mechanical Retrieval and Recanalization of Stroke Clots Using Embolectomy; $\mathrm{mRS}=$ modified Rankin Scale; NIHSS = NIH Stroke Scale; NINDS = National Institute of Neurological Disorders and Stroke; PROACT = Prolyse in Acute Cerebral Thromboembolism; SAINT = Stroke Acute Ischemic NXY-059 Trial; sICH = symptomatic intracranial hemorrhage; SRNH = successful recanalization with no hemorrhage; SWIFT = SOLITAIRE FR With the Intention For Thrombectomy; $\mathrm{TICI}$ = Thrombolysis in Cerebral Ischemia; $\mathrm{TIMI}=$ Thrombolysis in Myocardial Ischemia.

trial. ${ }^{46,47}$ The advantage of historical control is that all participants will receive the new intervention; this may resolve the ethical dilemma of some treating physicians and potentially may cut the trial cost and period in half. Selection bias and credibility are the main drawbacks of historical controls. The time difference between the historical control in a prior trial and the new trial time of enrollment may produce undetectable time-shift bias. Moreover, historical data are usually incomplete and lack uniformity.

If some of the historical control data can be used, then hybrid control could be considered. This would allow a combined contemporary randomized control plus historical control. ${ }^{48}$ The historical controls have to be recent, must share similar inclusion/ exclusion criteria, and must be enrolled by the same institution/investigators.

A multidimensional pooled control function model was created to pool data from all AIS control arms published between 1994 and 2008. ${ }^{49}$ This is an intriguing method allowing pooling of multiple con- trol groups according to baseline NIHSS score and age, but they still inherently share similar limitations of using historical controls. ${ }^{49}$

Finally, ongoing prospective outcome research registries may be used as control groups, but these may have similar limitations of missing data, selection bias, lack of oversight and protocol uniformity, and analysis complexity.

Bayesian design. The Bayesian approach for statistical inference in AIS trials has been debated. ${ }^{50-52}$ The true innovation of the Bayesian approach is seen in cancer trials, given the small population of specific cancer type and more patients interested in the intervention. ${ }^{53}$ The Acute Stroke Therapy by Inhibition of Neutrophils trial used the adaptive dose-response Bayesian approach in real-time decision-making, to the level of whether there is need for the next observation at all. ${ }^{54} \mathrm{~A}$ conventional approach to statistical inference in clinical trials is the "frequentists' approach," where there is a very restricted sense of probability. The Bayesian approach uses current available data to create historical 


\begin{tabular}{|ll|}
\hline Table $6 \quad$ Benefits and limitations of Bayesian approach & \\
Benefits & Limitations \\
- Hierarchical models: incorporates historical and & - Requires historical information \\
concurrent information & - Requires agreement on "known/historical" \\
- Decreases confounding bias & - Requires extensive preplanning \\
- Greater power or smaller sample size & - Requires statistical and computational expertise \\
- Tackles more complex problems & - Requires excessive computing power \\
- Flexibility of sequential monitoring & - Expert audition required \\
- More intuitive and meaningful inferences & \\
- Tailored to decision-making (simulates clinical \\
decision-making)
\end{tabular}

information (or posterior distribution) to create probabilities of future results (or anterior distribution). Moreover, the Bayesian approach could be used to determine when enough data are collected to create a statistically significant conclusion to the trial. Those 2 Bayesian features ensure that the power of the study is significant even with a limited sample size. The Bayesian approach is helpful in showing probability of relative effectiveness between 2 therapies with real-time adaptive statistics. $^{55,56}$ Some of the advantages and limitations of the Bayesian approach are listed in table 6. Bayesian approaches can provide a potential platform for device companies to create hierarchical models to increase power of studies using fewer subjects; however, more studies using this design are needed.

Test concepts with devices. In this paradigm, the clinical trial design is testing a concept with one or multiple devices. For example, the IMS trial premise of testing the endovascular concept rather than the efficacy of a single endovascular device would allow the flexibility for interventionalists to use what they believe would work best. ${ }^{13}$ If the study is positive for the interventional approach, it remains to be seen how the FDA would react. One advantage to such an approach is that a benchmark for clinical outcome in the standard of care and combined interventional approaches could be established.

IV regulatory considerations. The FDA clearance $(510(\mathrm{k}))$ process after a safety/angiographic efficacy single-arm trial with comparison to a predicate device (historical control) and, more recently, after device-vs- device trials, is a way to introduce the device into the market. There has been concern that devices are not held to the same approval standards as drugs. ${ }^{57}$ It is unknown which mechanical thrombectomy device can be tested in an RCT and when, since the feasibility of the new technology and identification of the right subgroup of patients are concerns.

FINANCIAL ASPECTS OF CLINICAL TRIALS Financial and logistic support. The 2 main criticisms of RCTs are the long duration and the cost. Endovascular AIS intervention trials are expensive and may be the right setup for joint sponsorship between national government funding agencies and industry. ${ }^{16-20}$ There are concerns about the credibility of the results and publication bias when industry is involved, however. ${ }^{58,59}$ If the studies are solely sponsored by industry, then they are likely not to be published if negative, and they are not likely to be completed if futility analysis is performed. ${ }^{58}$ It is important to assure the investigators that the industry sponsor guarantees no censoring of manuscripts, irrespective of the result. This underscores the importance of joint sponsoring of studies by a national agency and the medical device industry, to increase their credibility.

Costs of overtreatment are less than costs of undertreatment. Traditional paradigms for designing clinical trials have been based on the principle that a new treatment cost is less than the cost of standard treatment because of potential downstream savings 
on chronic care costs. This concept has significant implications for AIS stroke therapy with newer, expensive endovascular devices. Cost-effectiveness analysis of AIS endovascular trial design is a critical consideration for interested government and private insurance agencies.

Pay per procedure within and outside the trial. One intricate financial aspect of clinical trials is the financial complexity of payers, institutions, trialists, and proceduralists. The payers are asking to identify standard-of-care vs study-related activities. The proceduralists may have concerns about the consequences of a given trial result on the prospect of providing coverage to other patients outside the trial inclusion criteria, i.e., lack of generalizability. Such concerns may have a deleterious impact on the willingness of clinicians and industry to participate in future clinical trials.

REPORTING AND DATA ACCESS Publication and reporting of final results of AIS trials are often suboptimal in spite of recommendations to adhere to guidelines in publications. ${ }^{60}$ Publication of trial method design details should be mandated.

Reporting standards improved after the addition of Consolidated Standards of Reporting Trials (CONSORT) guidelines. ${ }^{10}$ Similar guidelines and standards for reporting AIS endovascular trials have been proposed. ${ }^{60}$ Standardization of reporting and data access is increasingly demanded by regulators and journals and would improve trial credibility and the ability to compare trial results.

CONCLUSION There are limited numbers of AIS interventional RCTs and single-arm prospective trials (selected ones are listed in tables 2 and 5). This scarcity underscores the significant challenges in designing trials in AIS. To address such complexity, it is critical to choose the most suitable outcome measures, control groups, and innovative overall designs.

\section{AUTHOR CONTRIBUTIONS}

All the authors participated in the writing and editing of the final manuscript.

\section{DISCLOSURE}

Dr. Zaidat serves on the scientific advisory board for Talecris; served on the adjudication committee for Stryker; received speaker honoraria from Stryker; served on the editorial board of Frontiers in Neurology (Endovascular \& Interventional Neurology Section); serves as Editor of The Journal of Neurointerventional Surgery, and serves as Associate Editor and is a member of the Editorial Board of Journal of Stroke \& Cerebrovascular Diseases; served as a consultant for Stryker Neurovascular-Commercial, Codman Neurovascular-Commercial, and Microvention Inc.-Commercial; and has received research support from a Society of Vascular \& Interventional Neurology (SVIN) grant for this educational activity. Dr. Liebeskind served as a consultant for Concentric Medical and CoAxia and receives research support from NIH. Dr. Edgell serves as an Associate
Editor, Frontier of Interventional Neurology. Dr. Amlie-Lefond is the principal investigator for the Thrombolysis in Pediatric Stroke trial. Dr. Kalia reports no disclosures. Dr. Alexandrov serves as an Associate Editor for Frontiers of Interventional Neurology, has a patent for "Therapeutic Methods and Apparatus for Use of Sonication to Enhance Perfusion of Tissue"; has received publishing royalties for Cerebrovascular Ultrasound in Stroke Prevention and Treatment and Cerebrovascular Ultrasound in Stroke Prevention and Treatment (2nd Edition); has served as a consultant for Cerevast Therapeutics; spends $60 \%$ effort on clinical stroke service at Comprehensive Stroke Center, UAB Hospital, monitoring endovascular procedures and evaluating success of recanalization with imaging; has received research support from Cerevast Therapeutics, Inc.; has received research support from NINDS; has received compensation from Cerevast Therapeutics, Inc.; and has received license fee payments from "Therapeutic Methods and Apparatus for Use of Sonication to Enhance Perfusion of Tissue." Go to Neurology.org for full disclosures.

Received July 10, 2011. Accepted in final form December 14, 2011.

\section{REFERENCES}

1. Amberson JB, McMahon BT, Pinner M. A clinical trial of sanocrysin in pulmonary tuberculosis. Am Rev Tuberc 1931;24:401-435.

2. Chimowitz MI, Lynn MJ, Howlett-Smith H, et al.; Warfarin-Aspirin Symptomatic Intracranial Disease Trial Investigators. Comparison of warfarin and aspirin for symptomatic intracranial arterial stenosis. N Engl J Med 2005;352:1305-1316.

3. Moskowitz SI, Kelly ME, Obuchowski N, Fiorella D. Impact of WASID and Wingspan on the frequency of intracranial angioplasty and stenting at a high volume tertiary care hospital. J NeuroIntervent Surg 2009;1:165-167.

4. Zaidat OO, Klucznik R, Alexander MJ, et al.; NIH Multicenter Wingspan Intracranial Stent Registry Study Group. The NIH registry on use of the Wingspan stent for symptomatic $70-99 \%$ intracranial arterial stenosis. Neurology 2008;70:1518-1524.

5. Chimowitz MI, Lynn MJ, Derdeyn CP, et al.; SAMMPRIS Trial Investigators. Stenting versus aggressive medical therapy for intracranial arterial stenosis. N Engl J Med 2011;365: 993-1003.

6. Molyneux A, Kerr R, Stratton I, et al.; International Subarachnoid Aneurysm Trial (ISAT) Collaborative Group. International Subarachnoid Aneurysm Trial (ISAT) of neurosurgical clipping versus endovascular coiling in 2143 patients with ruptured intracranial aneurysms: a randomised trial. Lancet 2002;360:1267-1274.

7. Brinjikji W, Rabinstein AA, Lanzino G, Kallmes DF, Cloft HJ. Effect of age on outcomes of treatment of unruptured cerebral aneurysms: a study of the National Inpatient Sample 2001-2008. Stroke 2011;42:1320-1324.

8. Liebeskind DS, Kidwell CS, Sayre JW, Saver JL. Evidence of publication bias in reporting acute stroke clinical trials. Neurology 2006;67:973-979.

9. Kidwell CS, Liebeskind DS, Starkman S, Saver JL. Trends in acute ischemic stroke trials through the 20th century. Stroke 2001;32:1349-1359.

10. Moher D, Schulz KF, Altman D. The CONSORT statement: revised recommendations for improving the quality of reports of parallel-group randomized trials. JAMA 2001;285:1987-1991.

11. Campbell G. Statistics in the world of medical devices: the contrast with pharmaceuticals. J Biopharm Stat 2008;18: $4-19$. 
12. Furlan A, Higashida R, Wechsler L, et al. Intra-arterial prourokinase for acute ischemic stroke: the PROACT II study: a randomized controlled trial. JAMA 1999;282: 2003-2011.

13. Khatri P, Hill MD, Palesch YY, et al. Methodology of the Interventional Management of Stroke III trial. Int J Stroke 2008;3:130-137.

14. Ciccone A, Valvassori L, Gasparotti R, Scomazzoni F, Ballabio E, Sterzi R. Debunking 7 myths that hamper the realization of randomized controlled trials on intra-arterial thrombolysis for acute ischemic stroke. Stroke 2007;38: 2191-2195.

15. STAIR-II Participants. Stroke Therapy Academic Industry Roundtable II (STAIR-II): recommendations for clinical trial evaluation of acute stroke therapies. Stroke 2001;32: 1598-1606.

16. Fisher M, Stroke Therapy Academic Industry Roundtable. Recommendations for advancing development of acute stroke therapies: Stroke Therapy Academic Industry Roundtable 3. Stroke 2003;34:1539-1546.

17. Fisher M, Albers GW, Donnan GA; Stroke Therapy Academic Industry Roundtable IV. Enhancing the development and approval of acute stroke therapies: Stroke Therapy Academic Industry Roundtable. Stroke 2005;36: $1808-1813$

18. Fisher M, Hanley DF, Howard G, Jauch EC, Warach S; STAIR Group. Recommendations from the STAIR V meeting on acute stroke trials, technology and outcomes. Stroke 2007;38:245-248.

19. Fisher M, Feuerstein G, Howells DW, et al.; STAIR Group. Update of the stroke therapy academic industry roundtable preclinical recommendations. Stroke 2009; 40 : 2244-2250.

20. Saver JL, Albers GW, Dunn B, Johnston KC, Fisher M; STAIR VI Consortium. Stroke Therapy Academic Industry Roundtable (STAIR) recommendations for extended window acute stroke therapy trials. Stroke 2009;40:25942600.

21. Philip M, Benatar M, Fisher M, Savitz SI. Methodological quality of animal studies of neuroprotective agents currently in phase II/III acute ischemic stroke trials. Stroke 2009; 40:577-581.

22. Guiloff RJ, ed. Clinical Trials in Neurology. London: Springer-Verlag; 2001.

23. Tomsick TA, Khatri P, Jovin T, et al.; IMS III Executive Committee. Equipoise among recanalization strategies. Neurology 2010;74:1069-1076.

24. Moskop JC. Informed consent and refusal of treatment: challenges for emergency physicians. Emerg Med Clin North Am 2006;24:605-618.

25. Lemaire F. Emergency research: only possible if consent is waived? Curr Opin Crit Care 2007;13:122-125.

26. US Department of Health and Human Services, Office for Human Research Protections. Informed consent. Available at: http://www.hhs.gov/ohrp/policy/consent/. Accessed February 2012.

27. Clark W, Gantt H. The Gantt Chart, a Working Tool of Management. New York: Ronald Press; 1922. Available at: www.clinicaldevice.com/. Accessed February 2012.

28. Davey Smith G, Egger M. Meta-analysis: unresolved issues and future developments. BMJ 1998;316:221-225.

29. Institute of Medicine. Initial National Priorities for Comparative Effectiveness Research. Washington, DC: National Academies Press; 2009.
30. Federal Coordinating Council for Comparative Effectiveness Research. Comparative effectiveness research funding. Available at: www.hhs.gov/recovery/programs/cer/. Accessed January 21, 2010.

31. Weaver CS, Leonardi-Bee J, Bath-Hextall FJ, Bath PM. Sample size calculations in acute stroke trials: a systematic review of their reporting, characteristics, and relationship with outcome. Stroke 2004;35:1216-1224.

32. Adams HP. Trials of trials in acute ischemic stroke: the Humana Lecture. Stroke 1993;24:1410-1415.

33. Olivot JM, Albers GW. Diffusion-perfusion MRI for triaging transient ischemic attack and acute cerebrovascular syndromes. Curr Opin Neurol 2011;24:44-49.

34. Khatri P, Abruzzo T, Yeatts SD, et al.; IMS I and II Investigators. Good clinical outcome after ischemic stroke with successful revascularization is time-dependent. Neurology 2009;73:1066-1072.

35. Mechanical Retrieval and Recanalization of Stroke Clots Using Embolectomy (MR RESCUE). Available at: http:// clinicaltrials.gov/ct2/show/NCT00389467?term $=\mathrm{MR}+$ RESCUE\&rank $=1$. Accessed February 2012.

36. Riedel CH, Zimmermann P, Jensen-Kondering U, Stingele R, Deuschl G, Jansen O. The importance of size: successful recanalization by intravenous thrombolysis in acute anterior stroke depends on thrombus length. Stroke 2011; 42:1775-1777.

37. Assess the Penumbra System in the Treatment of Acute Stroke (THERAPY). Available at: http://clinicaltrials.gov/ ct2/show/NCT01429350?term $=$ NCT01429350\&rank $=1$. Accessed February 2012.

38. Odgaard-Jensen J, Vist GE, Timmer A, et al. Randomisation to protect against selection bias in healthcare trials. Cochrane Database Syst Rev 2011;4:MR000012.

39. SOLITAIRE FR With the Intention For Thrombectomy (SWIFT) Study. Available at: http://clinicaltrials.gov/ct2/ show/NCT01054560?term $=$ SWIFT\&rank=1. Accessed February 2012.

40. Mancini GB, Schulzer M. Reporting risks and benefits of therapy by use of the concepts of unqualified success and unmitigated failure: applications to highly cited trials in cardiovascular medicine. Circulation 1999;99:377-383.

41. Young GA, Lees RK, Weir CJ, for the Glycine Antagonist in Neuroprotection (GAIN) International Trial Steering Committees and Investigators. Strengthening acute stroke trials through optimal use of disability end points. Stroke 2003;34:2676-2680.

42. Saver JL. Novel end point analytic techniques and interpreting shift across the entire range of outcome scales in acute stroke trials. Stroke 2007;38:3055-3062.

43. Broderick JP, Lu M, Kothari R, et al. Finding the most powerful measures of the effectiveness of tissue plasminogen activator in the NINDS tPA stroke trial. Stroke 2000; 31:2335-2341.

44. Lees KR. Neuroprotection is unlikely to be effective in humans using current trial designs: an opposing view. Stroke 2002;33:308-309.

45. Savitz SI, Lew R, Bluhmki E, Hacke W, Fisher M. Shift analysis versus dichotomization of the modified Rankin scale outcome scores in the NINDS and ECASS-II trials. Stroke 2007;38:3205-3212.

46. Penumbra Pivotal Stroke Trial Investigators. The penumbra pivotal stroke trial: safety and effectiveness of a new 
generation of mechanical devices for clot removal in intracranial large vessel occlusive disease. Stroke 2009;40: 2761-2768.

47. Smith WS, Sung G, Starkman S, et al. Safety and efficacy of mechanical embolectomy in acute ischemic stroke: results of the MERCI trial. Stroke 2005;36:1432-1438.

48. Pocock SJ. The combination of randomized and historical controls in clinical trials. J Chron Dis 1976;29:175-188.

49. Mandava P, Kent TA. A method to determine stroke trial success using multidimensional pooled control functions. Stroke 2009;40:1803-1810.

50. Donnan GA, Davis SM, Berry DA. Clinical trials: is the Bayesian approach ready for prime time? Yes! Stroke 2005; 36:1621-1622.

51. Donnan GA, Davis SM, Ludbrook J. The Bayesian principle: can we adapt? Stroke 2005;36:1623-1624.

52. Howard G, Coffey CS, Cutter GR. Is Bayesian analysis ready for use in phase III randomized clinical trials? Beware the sound of the sirens. Stroke 2005;36:1622-1623.

53. Berry DA. Statistical innovations in cancer research. Cancer Med 2003:465-478.

54. Krams M, Lees KR, Hacke W, Grieve AP, Orgogozo J, Ford GA. Acute Stroke Therapy by Inhibition of Neutrophils (ASTIN): an adaptive dose-response study of UK-279,276 in acute ischemic stroke. Stroke 2003;34: 2543-2548.

55. Diamond GA, Kaul S. Prior convictions: Bayesian approaches to the analysis and interpretation of clinical mega trials. J Am Coll Cardiol 2004;43:1929-1939.

56. Berry DA, Müller P, Grieve AP, et al. Adaptive Bayesian designs for dose-ranging drug trials. Case Studies Bayesian Stat 2001;99-181.

57. Pena C, Li K, Felten R, Ogden N, Melkerson M. An example of US Food and Drug Administration device regulation: medical devices indicated for use in acute ischemic stroke. Stroke 2007;38:1988-1992.

58. Dorman PJ, Counsell C, Sandercock P. Reports of randomized trials in acute stroke, 1955 to 1995 : what proportions were commercially sponsored? Stroke 1999;30:1995-1998.
59. Thornton A, Lee P. Publication bias in meta-analysis: its causes and consequences. J Clin Epidemiol 2000;53:207216.

60. Higashida RT, Furlan AJ, Roberts H, et al.; Technology Assessment Committee of the American Society of Interventional and Therapeutic Neuroradiol; Technology Assessment Committee of the Society of Interventional Radiology. Trial design and reporting standards for intraarterial cerebral thrombolysis for acute ischemic stroke. Stroke 2003;34:e109-e137.

61. Thrombectomy REvascularization of Large Vessel Occlusions in Acute Ischemic Stroke (TREVO). Available at: http://clinicaltrials.gov/ct2/show/NCT01088672?term= ischemic + stroke\&rank=7. Accessed February 2012.

62. Randomized Trial Evaluating Performance of the Trevo Retriever Versus the Merci Retriever in Acute Ischemic Stroke (TREVO2). Available at: http://clinicaltrials.gov/ ct2/show/NCT01270867. Accessed February 2012.

63. El Khoury R, Fisher M, Savitz SI. Current practice versus willingness to enroll in clinical trials: paradox among vascular neurologists about treatment for acute ischemic stroke. Stroke 2010;41:2038-2043.

64. Hacke W, Kaste M, Bluhmki E, et al. Thrombolysis with alteplase 3 to 4.5 hours after acute ischemic stroke. $\mathrm{N}$ Engl J Med 2008;359:1317-1329.

65. NINDS t-PA Stroke Study Group. Tissue plasminogen activator for acute ischemic stroke: the National Institute of Neurological Disorders and Stroke rt-PA Stroke Study Group. N Engl J Med 1995;333:1581-1587.

66. Shuaib A, Bornstein NM, Diener HC, et al.; SENTIS Trial Investigators. Partial aortic occlusion for cerebral perfusion augmentation: safety and efficacy of NeuroFlo in Acute Ischemic Stroke Trial. Stroke 2011;42: $1680-1690$.

67. Ogawa A, Mori E, Minematsu K, et al.; MELT Japan Study Group. Randomized trial of intraarterial infusion of urokinase within 6 hours of middle cerebral artery stroke: the Middle Cerebral Artery Embolism Local Fibrinolytic Intervention Trial (MELT) Japan. Stroke 2007;38:2633-2639. 


\section{Neurology}

\section{Clinical trial design for endovascular ischemic stroke intervention \\ Osama O. Zaidat, David S. Liebeskind, Randall C. Edgell, et al. \\ Neurology 2012;79;S221-S233 \\ DOI 10.1212/WNL.0b013e31826992cf}

This information is current as of September 24, 2012

Updated Information \&

Services

References

Permissions \& Licensing

Reprints including high resolution figures, can be found at:

http://n.neurology.org/content/79/13_Supplement_1/S221.full

This article cites 55 articles, 38 of which you can access for free at: http://n.neurology.org/content/79/13_Supplement_1/S221.full\#ref-list1

Information about reproducing this article in parts (figures,tables) or in its entirety can be found online at:

http://www.neurology.org/about/about_the_journal\#permissions

Information about ordering reprints can be found online:

http://n.neurology.org/subscribers/advertise

Neurology ${ }^{\circledR}$ is the official journal of the American Academy of Neurology. Published continuously since 1951, it is now a weekly with 48 issues per year. Copyright Copyright (? 2012 by AAN Enterprises, Inc.. All rights reserved. Print ISSN: 0028-3878. Online ISSN: 1526-632X.

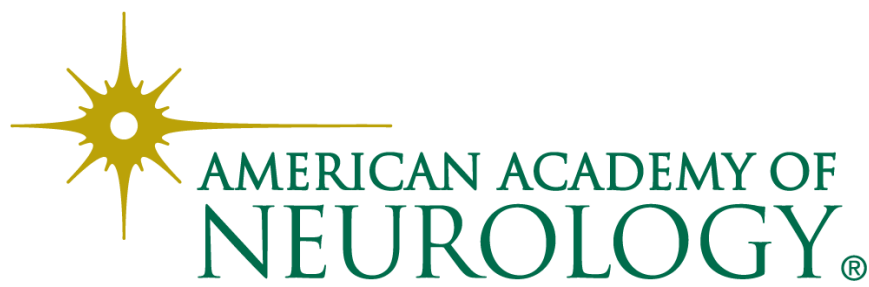

